\title{
LUDWIG WITTGENSTEIN: POST-TRACTATUS
}

Ludwig Wittgenstein fue uno de los filósofos más originales de este siglo y no cabe duda alguna de que el impacto de sus intuiciones acerca de la naturaleza de los problemas filosóficos cambiará, radical y permanentemente, el curso de la filosofía en el futuro. Infortunadamente la influencia de su pensamiento se ha demorado. Salvo un artículo en los Proceedings of the Aristotelian Society y su famoso Tractatus Logico-Philosophicus, Wittgenstein no permitió que ninguno de sus trabajos se publicara en vida, aun cuando algunas de sus lecciones circularon privadamente en forma mimeografiada entre un selecto grupo de sus alumnos. Según todas las versiones, Ludwig Wittgenstein era un hombre de una personalidad fuerte y tendía a congregar alrededor suyo un círculo de alumnos preferidos. Como es comprensible, una atmósfera semejante puede tener, y de hecho tuvo, consecuencias no tan deseables desde el punto de vista intelectual. El tiempo, por fortuna, ha comenzado ya a dispersar las brumas emotivas y a aclarar el aire; y ahora que la obra de Wittgenstein se ha vuelto accesible al público, ahora que, por asi decirlo, pertenece al dominio público, ésta se hará sentir amplia y objetivamente en la filosofía. Sin estirar una metáfora indebidamente, la filosofía hasta ahora podría describirse como un museo en continuo crecimiento, a la manera del de Madame Tussaud, al que constantemente se le agregan nuevas figuras, pero del que nunca se elimina ninguna. Pero algunas de las cosas que Wittgenstein dijo sembrarán una semilla en las mentes de los filósofos la cual, con el tiempo, dará lugar a una mayor comprensión de los mecanismos de la filosofía, permitiéndonos verla en una forma nueva. Y las explicaciones de las teorías y de los argumentos que se desprenderán de dicha comprensión no se convertirán simplemente en otros objetos de museo: colocarán, en cambio, esos objetos en una luz que nos permitirá verlos tal y como son.

A lo largo de los años la filosofía se le presentó a Wittgenstein bajo una serie de ropajes diferentes, algunos de ellos los usuales que todos conocemos, otros no. Naturalmente son las últimas formas como vio la filosofía las que son tan iluminadoras y útiles, pero para darse cuenta de cuanto lo son es necesario examinar algunas de las primeras. Antes de considerarlas, es importante, sin embargo, advertir una conexión entre algunas de las cosas que realizó G. E. Moore y las intuiciones acerca de la filosofía a que llegó Wittgenstein más tarde. Como es bien sabido, Moore bajó a la tierra las teorías filosóficas (o algunas de ellas cuando menos) del "cielo sobre los cielos" platónico donde se encontraban protegidas frente a nuestro entendimiento. Puestas a la luz del sol ordinario pueden exami- 
narse bajo condiciones menos deformantes. Una tesis filosófica general como la de Bradley, de que las cosas físicas no son reales, o son mera apariencia, la cual hechiza el intelecto, Moore la traduciria (y tal vez no sería exagerado decir la desinflaría) a sus implicaciones concretas, por ejemplo, de que él realmente no llevaba un chaleco o de que estaba equivocado en creer que había una hoja de papel sobre la que estaba escribiendo con una pluma fuente. El propósito aparente de Moore al llevar a cabo sus traducciones a lo concreto era dirigir nuestra atención hacia las consecuencias de una teoría filosófica abstracta, consecuencia que al parecer tendemos a pasar por alto. EI motivo para hacer esto, frecuentemente si no siempre, era refutar una teoría sometiéndola a "un juicio mediante ejemplos", pero lo que no podía menos que salir a la luz, ya sea que se le apresara consciente o inconscientemente, era que si se interpretaban las teorías como admitiendo las traducciones de Moore, eran demasiado obviamente falsas como para que alguien no advirtiera por sí mismo que lo eran. Otro rasgo curioso propio de las traducciones de Moore es el de que muchos filósofos que llegaron a conocerlas no abandonaron sus tesis. La idea que inevitablemente viene a la cabeza es la de que una tesis filosófica como "las cosas físicas son irreales" no es aquello por lo cual se la ha tomado. No puede menos que surgir la pregunta de si la tesis es en verdad incompatible con una proposición fáctica como la de que Moore viste un chaleco y está escribiendo con una pluma fuente. Por sorprendente que pueda parecer, las traducciones de Moore a lo concreto tendían a mostrar, si es que mostraban algo, que las teorías no permitían sus traducciones. El problema se vuelve, entonces, el de comprender correctamente cómo está usando el lenguaje un filósofo que dice "las cosas físicas no son reales", o "las cosas físicas existen, pero son mera apariencia". La obra posterior de Wittgenstein nos muestra el camino para llegar a una comprensión correcta de este tipo de enunciados.

En alguna parte Moore observó que parecería que el lenguaje, el lenguaje común y corriente de todos los días, fue "expresamente ideado para descarriar a los filósofos". ${ }^{1}$ Al parecer con la misma queja en la cabeza, Wittgenstein dijo que "La filosofía es una batalla en contra del hechizo de nuestro entendimiento por medio de nuestro lenguaje", y "un problema filosófico tiene la siguiente forma 'no me oriento" ". Moore recurrió a un procedimiento, el del análisis cuidadoso de los significados de las palabras, para liberar a los filósofos del hechizo de las palabras. También Wittgenstein empleó este procedimiento para ayudarlos a encontrar su camino a través del laberinto del lenguaje. Según él: "Una de las fuentes principales de nuestras incomprensiones es que no abarcamos en su conjunto el uso de nuestras palabras. Nuestra gramática carece de este tipo de claridad."

Para expresar esto con la ayuda de una metáfora de Wittgenstein que ha capturado la imaginación de muchos filósofos, lo que ayudará a la mosca a

1 Philosophical Studies, p. 217.

2 Philosophical Investigations, p. 47. Para la traducción de las citas de la versión inglesa se tomó en cuenta el original alemán.

3'Ibid, p. 49. 
escapar de la botella es un análisis del uso, llegar a saber cómo usamos las palabras ordinariamente. Hay, sin embargo, una diferencia en los procedimientos de ambos que es útil advertir. Esta diferencia podría muy bien haber llevado a Wittgenstein a decir que un filósofo del Sentido Común ("y ese, y $n$. $b$., no es el hombre de sentido común") ${ }^{4}$ también se encuentra preso dentro de la botella, pero tiene preferencia por un rincón especial, y a decir que al tratar de refutar posiciones que van en contra del sentido común tampoco él "se orienta". Porque los desacuerdos de Moore con los filósofos terminan en unos empates filosóficos, empates tan viejos como aquéllos entre Parménides y sus oponentes.

Se recordará que la defensa que hizo Moore del sentido común en contra de los ataques de los filósofos, ataques sostenidos a través de la larga historia de la filosofía, ha sido rechazada por cometer una petición de principio y que Moore ha sido criticado por ser dogmático en cuanto a los "truismos" que formuló. $\mathrm{Y}$ al proponerlos, sin apoyarlos en ningún razonamiento, en contra de las tesis opuestas de los filósofos que fundamentan sus propias proposiciones con argumentos analíticos, cometió, en la opinión de muchos pensadores, una petición de principio relativa a las cuestiones mismas que se debaten. Las interjecciones usuales de Moore "sin sentido", "absurdo", "obviamente falso", etc., pueden silenciar pasajeramente a un filósofo que va en contra del Sentido Común, pero no afecta la forma en que continúa pensando acerca de los "errores" del Sentido Común. Hace mucho Parménides dijo "No atiendas al ciego ojo, a la resonante oreja, ni tampoco a la lengua, sino utiliza en esta gran disputa el criterio de la razón". Podríamos interpretar esta receta filosófica de la siguiente manera, sin prejuzgar acerca del problema de si nuestros sentidos son o no son fuentes seguras de información: no hagas caso del ojo, del oído y de la lengua (pues todos nosotros en buena medida oímos lo mismo, gustamos lo mismo, y vemos lo mismo), y emplea sólo el razonamiento en una investigación filosófica. La defensa de Moore no hace esto. Moore, por ejemplo, concede que no da, ni intenta dar, un argumento en favor de las premisas de lo que propone como prueba de la existencia de las cosas externas; y un filósofo que da argumentos en contra de la tesis del Sentido Común de que nosotros tenemos conocimiento de la existencia de cosas tales como chalecos y plumas podría, con cierta apariencia de justificación, acusar a Moore de dogmatismo y de petición de principio. $Y$ Moore, en verdad, necesita explicar por qué el llamar la atención de los filósofos sobre las verdades del Sentido Común no los hace volver a él ni los hace abandonar sus tercos ataques. Pero tal vez sólo pueda encontrarse una explicación viendo la filosofía desde una perspectiva exterior a ella, sólo desde una posición exterior será posible ver la naturaleza de los empates filosóficos.

Puede decirse con justicia que Wittgenstein ha sido leído recientemente con demasiada prisa y que algunas de sus ideas han sido pasadas por alto y otras han

${ }^{4}$ L. Wittgenstein, Preliminary Studies for the "Philosophical Investigations" Generally Known as the Blue and Brown Books, p. 48. En ulteriores referencias llamaremos a este trabajo The Blue Book. 
sido puestas al servicio de las necesidades privadas de los filósofos, con consecuentes lagunas y distorsiones en la comprensión que tenemos de su obra posterior. En lo tocante al punto que nos interesa, es importante leer con especial cuidado uno de sus pasajes relativos a lo que sucede cuando nosotros filosofamos y en qué forma debemos volver de la filosofía al sentido común sin regresar al mismo tiempo a la filosofía. El pasaje muestra también cómo su procedimiento difiere del de Moore. Moore, en general, representa al filósofo que se separa del Sentido Común como habiendo cometido un error de hecho; Wittgenstein, frecuentemente, lo representa como habiendo cometido un error de lenguaje, e identifica el error con el fin de lograr una curación. El pasaje es el siguiente:

Guando nosotros pensamos en la relación que tienen los objetos que nos rodean con nuestras experiencias personales de ellos, a veces estamos tentados a decir que esas experiencias personales son el material en que consiste la realidad. Cómo surge esta tentación se aclarará posteriormente.

Guando nosotros pensamos en esta forma, parece que perdemos nuestra seguridad con respecto a los objetos que nos rodean. $Y$ en su lugar nos encontramos con una serie de experiencias personales separadas de individuos diferentes. Estas experiencias personales, nuevamente, parecen vagas y parecen estar en un flujo constante. Nuestro lenguaje no parece haber sido hecho para describirlas. Estamos tentados a pensar que para aclarar filosóficamente estos asuntos, nuestro lenguaje ordinario es demasiado burdo, que necesitamos un lenguaje más sutil.

Parece que hubiésemos hecho un descubrimiento - que yo podría describir diciendo que se descubrió que el suelo sobre el que estábamos, que parecía ser firme y seguro, era pantanoso e inseguro-. Es decir, esto sucede cuando nosotros filosofamos; porque tan pronto como volvemos al punto de vista del sentido común esta incertidumbre general desaparece.

Esta extraña situación puede aclararse un poco fijándonos en un ejemplo; en verdad una especie de parábola que ilustra la dificultad en la que nos encontramos y que también muestra la salida a este tipo de dificultad: los científicos populares nos han dicho que el piso en el que estamos parados no es sólido, tal como le aparece al sentido común, pues se ha descubierto que la madera consiste de partículas que llenan el espacio en una forma tan sutil que casi puede llamársele vacio. Esto es susceptible de crear en nosotros una perplejidad, porque en cierta forma sabemos, naturalmente, que el piso es sólido, o que si no es sólido, esto puede deberse a que la madera está podrida, pero no al hecho de que está compuesta de electrones. Decir, basándonos en esto, que el piso no es sólido es usar el lenguaje indebidamente. Porque aun si las partículas fueran tan grandes como granos de arena y estuviesen tan juntas como lo están en un montón de arena, el piso no sería sólido si estuviese compuesto de ellas en el sentido en que un montón de 
arena está compuesto de granos. Nuestra perplejidad se basaba en una mala comprensión; la imagen de un espacio sutilmente lleno ha sido aplicada erróneamente. Pues esta imagen de la estructura de la materia tenía que explicar justamente el fenómeno de la solidez.

Asi, como en este ejemplo la palabra "solidez" estaba usada erróneamente y parecía que nosotros hubiésemos mostrado que nada realmente era sólido, exactamente en esta forma, al enunciar nuestras perplejidades acerca de la vaguedad general de la experiencia sensible y acerca del flujo de todos los fenómenos, nosotros estamos usando las palabras "flujo" y "vaguedad" erróneamente y en una forma típicamente metafísica, a saber, sin una antítesis; mientras que en su uso correcto y cotidiano, la vaguedad se opone a la claridad, el flujo a la estabilidad. ${ }^{5}$

Examinar una proposición filosófica de esta manera es una ayuda enorme, pero no es suficiente. Y Wittgenstein fue más allá de este punto de vista llegando a intuiciones más profundas acerca del modo cómo funciona la filosofía, como se ve, por ejemplo, en su caracterización de un problema filosófico como un problema que surge "cuando el lenguaje está de vacaciones",, o "cuando el lenguaje es como una máquina que gira en vacío, no cuando está trabajando".7 La implicación obvia de estas observaciones y de muchas otras cosas que dijo es la de que un problema filosófico no es una simple confusión verbal que haya que aclararse analizando el uso, sino que más bien es la expresión de una clase especial de juego que puede ejecutarse con el lenguaje. Según esta interpretación de lo que es hacer filosofía, resolver un problema filosófico es simplemente comprender el juego que se lleva a cabo con la terminología.

Volviendo a su primera obra, Wittgenstein en el Tractatus enuncia un número de tesis acerca de la naturaleza de la filosofía o de alguna de sus partes. Los siguientes enunciados ejemplifican las tesis más importantes propuestas por él:

1. La mayoría de las proposiciones y cuestiones que se han escrito sobre asuntos filosóficos no son falsas sino sinsentido. Por tanto, no podemos responder en ninguna forma a cuestiones de este tipo, sino sólo podemos establecer que son un sinsentido... Y no es sorprendente que los problemas más profundos no son en realidad problema alguno. (4.003).

2. La filosofía no es una doctrina sino una actividad. Un trabajo filosófico consiste esencialmente de elucidaciones. El resultado de la filosofía no son "proposiciones filosóficas", sino la clarificación de las proposiciones. (4.112).

3. Toda filosofía es "crítica del lenguaje"... (4.0031).

4. La totalidad de las proposiciones verdaderas es el conjunto de la ciencia natural (o la totalidad de las ciencias naturales). (4.11).8

5 The Blue Book, pp. 45-6.

6 Philosophical Investigations, p. 19.

7 Ibid, p. 51. . 
Las inconsistencias entre estas cosas diferentes que Wittgenstein dijo acerca de la filosofía no son insignificantes, y el que hayan pasado sin que se advirtieran debe tener una explicación. Pero señalar inconsistencias no es importante en este momento. Lo que es importante ver es que la filosofia pudo presentarle caras tan diferentes. Acerca de sus propios enunciados en el Tractatus, posiblemente aquellos relativos a la filosofía, dijo: "Mis proposiciones sirven como elucidaciones de la siguiente manera: que quien me entiende terminará reconociéndolas como sinsentido, cuando las ha usado --como escalones- para ascender sobre ellas. (Debe, por así decirio, arrojar la escalera después que se ha subido en ella.) Debe superar estas proposiciones, entonces verá el mundo correctamente." (6.54).

Esta declaración, que muchas gentes encontraron excitante, es cuando menos extraña, y el interés que suscita debe derivarse de algún tipo de mensaje oculto que transmite. Tal vez, como el oráculo Délfico, "ni dice, ni oculta, sino hace señales". Aparentemente la declaración parece implicar que sus propios enunciados son elucidaciones sinsentido y, por tanto, según sus propias palabras, que las elucidaciones sinsentido pueden llevar a alguien a ver el mundo correctamente. La implicación que subyace parecería ser la de que los filósofos no ven el mundo correctamente y de que el sinsentido puede conducirlos a que lo vean correctamente. Se concederá que el sinsentido parece a veces tener notables poderes curativos, pero es difícil pensar que pueda ser un "medicamento eficaz" para los filósofos. Sea esto como fuere, la serie de tesis que Wittgenstein propuso, explícitamente o por implicación, acerca de la filosofía son las siguientes: a) la mayoría de las aserciones filosóficas carecen de inteligibilidad literal, a la manera en que "Io bueno es más idéntico que lo bello" carece de inteligibilidad literal. b) Ninguna proposición filosófica es verdadera. Esto se sigue directamente de (4) y es paralelo a algo que dijo en épocas posteriores: Lo que dicen los filósofos (de cualquier posición) está totalmente equivocado, pero lo que dice el criado es totalmente cierto.9 También parece haber sostenido c) que algunas proposiciones filosóficas son verdaderas. Así salió en apoyo de una de las tesis de Hume sobre causalidad: "La creencia en el nexus causal es superstición." (5.1361); y también sostuvo la tesis de que una proposición acerca del futuro es una hipótesis: "Es una hipótesis que el sol saldrá mañana: y esto quiere decir: Nosotros no sabemos si saldrá." (6.36311) (d). Sostuvo, además, que en filosofía no se adelantan proposiciones. Según una de las formas en que se le presentó la filosofía, ésta era simplemente análisis aclaratorio y no tenía ninguna proposición propia que adelantar: no hay "proposiciones filosóficas" como hay proposiciones científicas.

8 Para la traducción de las citas se confrontó la versión inglesa de P. F. Pears y B. F. McGuinness con el original.

9 De las notas tomadas por A. Ambrose y M. Masterman en los intervalos entre los dictados del The Blue Book. Subsecuentemente nos referiremos a estas notas como The Yellow Book, que no ha sido publicado. 
La afirmación (a) de que la mayoría de las proposiciones filosóficas carecen de inteligibilidad literal usualmente está ligada con el llamado Principio de Verificabilidad, el cual exige algún comentario. Moritz Schlick formuló de la siguiente manera el principio para determinar si una oración indicativa que no expresa una proposición a priori tiene o carece de significación literal: "Enunciar el significado de una oración equivale a enunciar la regla según la cual hay que usar la oración y esto es lo mismo que enunciar la forma en que puede verificarse (o falsificarse). El significado de una proposición es el método de su verificación."10

Esta versión del principio se atribuye usualmente a Wittgenstein y probablemente se originó con él. Se ha creído comúnmente, tanto por aquellos que lo adoptaron como por quienes lo rechazaron, que eliminaba las oraciones metafísicas de la clase de las oraciones literalmente significativas construibles en un lenguaje, liberando de este modo a la filosofía de su rama más espectacular aunque más insatisfactoria. Esta idea acerca de cuál es la función del criterio concuerda con una serie de enunciados en el Tractatus; una lectura cuidadosa de la formulación del criterio revela, sin embargo, el hecho curioso de que no elimina a la metafísica y ciertamente contiene dentro de sí la posibilidad de que retorne aquello que se rechazó. Porque el criterio, tal como se formuló, no excluye la posibilidad de que haya una verificación suprasensible, que sería la clase de verificación apropiada a un enunciado que se refiriese a una realidad no-sensible. Esto es, tal como está formulado ( $y$ no puede suponerse que la formulación sea el resultado de un simple desliz accidental), el criterio está abierto a la siguiente especificación, "El significado de una proposición metafísica es el método de su verificación." El criterio no excluye las afirmaciones de un filósofo como Husserl, quien escribió: "Bajo el título de una 'Fenomenología Pura o Trascendental', el trabajo que aquí se presenta intenta fundar una nueva ciencia - aun cuando, en verdad, el entero curso del desarrollo filosófico desde Descartes ha ido preparando el camino para ella- una ciencia que cubre un nuevo campo de experiencia, exclusivamente propio, el de la "subjetividad trascendental'." 11

En relación a lo que nos ocupa es particularmente interesante advertir que una idea acerca de la filosofía expresada en el Tractatus (4.113) es la de que "resuelve controversias acerca de los límites de la ciencia natural". Esto parecería indicar la tesis de que una de las tareas de la filosofía es, cuando menos, la de resolver disputas territoriales entre la ciencia y la religión. La idea subyacente, de la cual Wittgenstein tal vez nunca se liberó completamente, es la de que el metafísico es capaz de contemplar la realidad en todas sus partes tanto suprasensibles como sensibles, y que al igual que el guía en el enredijo de Hampton Court, está en condiciones de ayudar a aquellos que se pierden en el laberinto cósmico.

10 Gesammelte Aufsätze, $1926-1936$ (1938). p. 340.

11 Edmund Husserl, Ideas, General Introduction to Pure Phenomenology, Trans. by W. R. Boyce Gibson (1931), p. 11. 
Esta idea puede tener muchas conexión con el hecho de que un cierto número de discípulos de Wittgenstein han vuelto a la metafísica. Ha de mencionarse, sin embargo, que cuando menos un seguidor de Wittgenstein ha tomado un camino diferente, que está de acuerdo con el criterio. Según él una de las tareas de la filosofía, tal vez su única tarea, es la de aclarar los modos de verificación apropiados a los diferentes tipos de proposiciones. Es interesante señalar que la lógica, según Aristóteles, tiene una función similar. Ross describe la concepción de la lógica de Aristóteles como no siendo "una ciencia independiente, sino una parte de la cultura general por la cual toda persona debe pasar antes de estudiar cualquier ciencia, siendo la única que le permitirá saber respecto de qué clases de proposiciones debe exigir pruebas y qué clases de prueba debe exigir para ellas." 12

Volvamos a las cuatro tesis diferentes e incompatibles acerca de la filosofía que se encuentran en el Tractatus: a) La mayoría de las proposiciones filosóficas carecen de sentido, $b$ ) Las proposiciones filosóficas no son verdades, c) Algunas proposiciones filosóficas son verdades, d) No hay proposiciones filosóficas. Estas tesis se encuentran muy cómodamente las unas junto a las otras y no hay prueba de que Wittgenstein intentara alguna vez ordenerlas y seleccionar entre ellas. No puede suponerse, sin embargo, que en la mente activa y original de Wittgenstein pudieran indefinidamente continuar viviendo en buenos términos las unas con las otras. Y su existencia muestra de manera inequívoca que una de sus preocupaciones principales, tal vez su preocupación central, fue la de llegar a tener una idea clara acerca de la naturaleza de la filosofía. En su pensamiento posterior Wittgenstein no se liberó completamente de sus primeras tesis acerca de la filosofía. Unos cuantos ejemplo serán suficientes para mostrar esto. En las Investigaciones Filosóficas escribe: "Los resultados de la filosofía son el descubrimiento de algún simple sinsentido y chichones que ha recibido el entendimiento al embestir contra los límites del lenguaje", ${ }^{13}$ y también "Lo que yo quiero mostrar es lo siguiente: pasar de un sinsentido que no es patente a uno que es patente". ${ }^{4}$ En el The Blue Book a veces parece presentar a los filósofos como adelantando tesis empíricas falsas, aun cuando en este punto no está de acuerdo con Moore en cuanto a la forma cómo debe corregírseles. Wittgenstein escribió:

No hay ninguna respuesta del sentido común a un problema filosófico. Uno sólo puede defender al sentido común en contra de los ataques de los filósofos solucionando sus perplejidades, esto es, curándolos de la tentación de atacar al sentido común, y no volviendo a plantear las tesis del sentido común. Un filósofo no es un demente, un hombre que no ve lo que todo el mundo ve; por otra parte, su desacuerdo con el sentido común no es igual al del científico que no está de acuerdo con las tesis burdas del hombre de la calle. ${ }^{15}$

12 W. D. Ross, Aristotle (1930), p. 20.

13 p. 48.

14 Ibid, p. 133. 
A veces Wittgenstein se representa a los filósofos como proponiendo tesis equivocadas acerca de los usos de la terminología, tesis que sus propias investigaciones pretenden corregir. Wittgenstein describe lo que hace con las siguientes palabras:

Nuestra investigación es, por consiguiente, una reflexión gramatical. Y esta investigación arroja luz sobre nuestro problema en tanto que elimina equívocos. Equívocos relativos al uso de las palabras; motivados, entre otras cosas, por ciertas analogías entre las formas de expresión en diferentes regiones de nuestro lenguaje. Muchos de ellos pueden eliminarse substituyendo una forma de expresión por otra; esto puede llamarse un "análisis" de nuestras formas de expresión, pues el proceso muchas veces es parecido a un descomponer. ${ }^{16}$

\section{También escribió:}

Cuando los filósofos usan una palabra - "saber", "ser", "objeto", "yo", "proposición", "nombre" - y tratan de apresar la esencia de la cosa, se debe siempre preguntar: ¿Se usa esta palabra realmente así en el lenguaje que es su tierra natal?

Nosotros volvemos a llevar las palabras de su empleo metafísico a su empleo cotidiano. ${ }^{17}$

A veces parece que presenta al filósofo como cometiendo dos diferentes clases de errores simultáneamente, uno un error fáctico, que debe eliminarse mediante el examen de las cosas o mediante la introspección, el otro un error lingüístico que se eliminará fijándose a qué se aplica normalmente una expresión. Así en el The Blue Book dijo: "Examina expresiones como: 'tener una idea en la cabeza', 'analizar una idea que tenemos ante nuestra mente'. Para que no te engañen fíjate en lo que sucede realmente cuando, por ejemplo, al escribir una carta estás buscando las palabras que expresen correctamente la idea que 'está ante ti'." 18 En base a esto podemos suponer que un platónico, por ejemplo, es llevado a sostener una creencia fáctica falsa acerca de lo que hay ante nuestra mente; una analogía lingüística lo lleva, erróneamente, a formarse una noción equivocada de la verdadera aplicación de la expresión "analizar una idea que tenemos ante nuestra mente" (compárese con el uso de la expresión "analizar una substancia que se encuentra ante nuestros ojos"). Esto a su vez resulta en una creencia falsa relativa a lo que hay ante nuestra mente cuando se lleva a cabo un análisis. La impresión que se logra es la de que ambos errores deben corregirse examinando

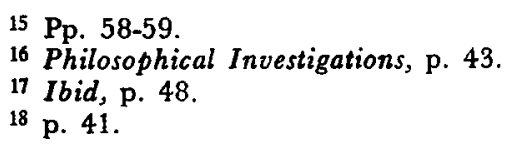


los hechos, tanto la idea errónea acerca del uso como la idea errónea acerca de lo que ocurre cuando "tenemos una idea ante nuestra mente". Pero obviamente el supuesto "error lingüístico" del platónico, quien parece pensar que hay objetos especialmente refinados que son designados por la frase "idea ante nuestra mente", no es igual al de una persona que piensa que la palabra "caballo" se usa normalmente para aplicarla a las vacas o igual al de una persona que ve un caballo pero piensa que ve una vaca o piensa que ve lo que de hecho no existe. Wittgenstein no pudo dejar de darse cuenta de esto $\mathrm{y}$, en verdad, una nueva intuición acerca de la filosofía había comenzado a formarse en su mente.

La dirección de su pensamiento se fue orientando cada vez más hacia la noción de que los problemas filosóficos son confusiones, embrollos lingüísticos que deben solucionarse volviendo al uso ordinario, con la ayuda de un recurso que llamó "juegos de lenguaje". Al filósofo se le forma un "calambre mental" y la terapia para eliminarlo es regresarlo al uso ordinario. El pasaje siguiente del The Blue Book aclarará esto. Al considerar la cuestión acerca de si yo puedo saber o creer que alguien siente un dolor, escribió:

¿Pero no es esta una pregunta extraña? ¿Es que no puedo yo creer que alguien tiene dolores? ¿ No es acaso sumamente fácil creer esto? - ... no hay necesidad de decir que nosotros no sentimos estas dificultades en la vida ordinaria. Tampoco es cierto decir que la sentimos cuando examinamos nuestra experiencia mediante introspección. . . Pero de alguna,manera cuando nosotros las vemos en una cierta forma, nuestra expresión es susceptible de embarullarse. Parece como si tuviésemos o las piezas equivocadas o bien no tuviésemos suficientes piezas para armar nuestro rompecabezas. Pero ellas están allí, sólo que todas revueltas; . . ${ }^{19}$

Lo que hay que hacer para componer las cosas, para curar nuestra enfermedad verbal, es "fijarse cómo las palabras en cuestión se usan realmente en nuestro lenguaje". ${ }^{20}$ Cuando Wittgenstein hizo la observación de que llamar "filosofía" a lo que hizo era tal vez justo, pero también engañoso, y de que su obra era uno de los "herederos" de la filosofía, ciertamente pensaba en la técnica de examinar el uso real de las expresiones en el lenguaje con el propósito de "disolver" los problemas filosóficos. Es digno de notarse, de paso, que Wittgenstein concibió su obra como algo benéficamente destructivo. Así dijo: "¿De dónde deriva su importancia nuestra investigación puesto que sólo parece destruir todo lo que es interesante, esto es, todo lo que es grande e importante? (Todos los edificios, por así decirlo, dejando sólo pedazos de piedra y cascote.) Lo que estamos destruyendo no son más que castillos de arena y limpiamos el suelo del lenguaje sobre el que se asientan." 21

19 P. 46.

20 lbid., p. 56.

21 Philosophical Investigations, p. 48. 
Volviendo a la cuestión de si lo que hizo podría con propiedad llamarse filosofía, Wittgenstein pensaba no sólo en el procedimiento consistente en intentar resolver las controversias examinando el uso - bajando así a los filósofos a las realidades lingüísticas - sino también, posiblemente, en la nueva noción que comenzaba a formarse. Debe concederse que Wittgenstein no formuló mucho esta intuición acerca de la estructura lingüística de las teorías filosóficas que fue la que dio lugar a esta noción, ni tampoco la elaboró y la desarrolló; pero la expresó en cierta medida e hizo cierta aplicación de ella. En The Blue Book se encuentra este importante parágrafo:

La persona que dice "sólo mi dolor es real" no quiere decir que ha descubierto mediante los criterios comunes —esto es, los criterios que le dan a nuestras palabras sus significados comunes- que las otras personas que dijeron que tenían dolores estaban engañando. Sino que aquello en contra de lo cual se rebela es el uso de esta expresión en conexión con estos criterios. Esto es, él objeta usar esta palabra en la forma particular como se usa comúnmente. Por otra parte no es consciente de que está objetando una convención. Ve la manera de dividir el territorio en forma diferente de la que se usa en una mapa ordinario. Se siente tentado, digamos, a usar el nombre "Devonshire" no como el nombre del condado con sus límites convencionales, sino como el de una región delimitada en forma diferente. Podría expresar esto diciendo: " $¿$ No es absurdo hacer de esto un condado, trazar los límites aqui?" Pero lo que dice es lo siguiente: "El verdadero Devonshire es éste." Podríamos responder: "Lo que tú quieres es solamente una nueva notación, y mediante una nueva notación no se cambia ningún hecho de la geografía." Es verdad, sin embargo, que nosotros podemos estar irresistiblemente atraídos o repelidos por una notación. (Olvidamos fácilmente cuánto puede significar para nosotros una notación, una forma de expresión, y que cambiarla no es siempre tan fácil como a menudo lo es en matemáticas o en las ciencias. Un cambio de ropas o de nombres puede significar muy poco y puede significar mucho.) ${ }^{22}$

La idea que sin equívoco alguno surge de este pasaje es la de que una teoría filosófica es.la introducción, expresada en forma engañosa, de una cierta terminología alterada. La forma de la oración en la que el filósofo presenta su reconstrucción del lenguaje convencional es la forma de la oración que se usa ordinariamente para enunciar un hecho empírico; y al presentar en esta forma su terminología rehecha se engaña a sí mismo con respecto a lo que hace, así como engaña a cualquier otra persona ya sea que esté de su parte o se le oponga. El filósofo se imagina a sí mismo como expresando un hecho empírico o una teoría, esto es, como pronunciándose acerca de lo que realmente es el caso o acerca de lo que existe o acerca de lo que no puede existir; y su error consiste en la inter-

22 P. 57. 
pretación que le da a lo que está haciendo, no en su comprensión del uso real de la terminología. Está equivocado acerca de lo que él hace con las convenciones del uso, no está equivocado en relación a cuáles son las convenciones aceptadas: "La falacia que nosotros podemos evitar es ésta: cuando rechazamos una determinada forma de simbolismo estamos inclinados a ver esto como si hubiésemos rechazado una proposición como falsa. Es erróneo comparar este rechazo de una unidad de medida como si fuera el rechazo de la proposición 'La silla tiene tres pies de altura en lugar de dos'. Esta confusión permea toda la filosofía. Es la misma confusión que considera que un problema filosófico se ocupa de un hecho del mundo en lugar de verlo como un asunto de expresión." 23

Esta tesis relativa a la naturaleza de los enunciados filosóficos y de lo que podría llamarse la "falacia de la filosofía" tiene, obviamente, una gran fuerza explicativa. La posición de que las proposiciones filosóficas son acerca de estados de cosas, acerca de la realidad, no se conforma, en primer lugar, con los argumentos analíticos mediante los cuales los filósofos apoyan sus teorías; tampoco explica, en segundo lugar, cómo un filósofo puede sostener sus tesis no siendo, para utilizar las palabras de Wittgenstein, "un demente, un hombre que no ve lo que todo mundo ve". La posición de que las proposiciones filosóficas utilizan el lenguaje en forma impropia o de que son descripciones erróneas del uso real no explica por qué no se refuta a un filósofo llevando otra vez la terminología a su "tierra natal". No explica por qué un filósofo a quien se le ha turbado mostrándole el uso correcto del lenguaje, no abandona su tesis o si la abandona por qué es susceptible de volver a ella más tarde. La tesis que explica las proposiciones filosóficas como siendo enunciados que encierran, en forma oculta, nuevos criterios para el uso de expresiones, explica ambas cosas y también explica otras excentricidades propias de las teorías filosóficas. Para usar la imaginativa metáfora de Wittgenstein, explica por qué no puede mostrársele a la mosca la manera de salir de la botella. No puede sacarse la mosca porque no quiere que la saquen. Sólo en un sentido superficial es la botella su cárcel. En un nivel más profundo, la botella es la morada que se ha creado con el lenguaje.

Un pasaje algo extenso del The Yellow Book parecería indicar, en forma bastante obvia, que esta fue la dirección que tomó su pensamiento en lo tocante a la naturaleza del teorizar filosófico, esto es, en lo tocante a lo que ocurre cuando nosotros pensamos en un "momento filosófico", para usar la expresión de Moore. Debe señalarse inmediatamente que el pasaje no indica sin ambigüedad y en forma clara esta dirección, habiendo indicaciones de otras direcciones. Pero la mente de Wittgenstein no parece que trabajaba a lo largo de líneas rectas. El pasaje es el siguiente y bien merece una lectura cuidadosa:

Supón ahora que yo llamo a mi cuerpo con el nombre de Wittgenstein. Entonces puedo decir "Wittgenstein tiene dolor de muelas, de la misma ma-

23 The Yellow Book. 
nera que puedo decir "Shaw tiene dolor de muelas". Por otra parte yo tendría que decir "yo siento dolor" y podría sentirlo en un momento en que Wittgenstein no tuviera el dolor de muelas; o cuando Shaw lo tuviera. Es sólo una cuestión de hecho el que Wittgenstein tenga el dolor de muelas cuando yo siento el dolor.

Si uso "yo" y "Wittgenstein", entonces "yo" ya no se opone a nada. Por consiguiente deberiamos usar un tipo diferente de notación. Podríamos hablar de dolor en un caso y de conducta en el otro. ¿ Pero esto significa lo mismo que decir que yo tengo un verdadero dolor de muelas y que la otra persona no lo tiene? No, porque la palabra "yo" ha desaparecido ahora del lenguaje. Ahora sólo podemos decir "hay dolor de muelas", localizarlo y describir su naturaleza.

Al hacer esto estamos conservando el lenguaje ordinario y a su lado estoy colocando otro. Todo lo que se dice en uno de ellos puede, naturalmente, decirse en el otro. Pero cada uno de ellos traza diferentes límites; arregla los hechos en forma diferente. Lo curioso acerca de una notación ordinaria es que traza un límite alrededor de un conjunto de experiencias más bien heterogéneas. Este hecho tienta a la gente a proponer otra notación en la que ya no hay tal cosa como el propietario de un dolor de muelas. Pero sin gentes que se den cuenta de ello o inclusive que se den cuenta de que hay dos, las dos notaciones chocan entre sí.

En otra forma. La respuesta a la persona que dice "Sólo yo puedo tener un verdadero dolor de muelas" debería ser "Si sólo tú puedes tener un verdadero dolor de muelas" no tiene sentido decir "Sólo yo puedo tener un verdadero dolor de muelas". O bien no necesitas el "yo" o bien no necesitas "verdadero". Tu notación establece demasiadas especificaciones. Harías mejor en decir "hay dolor de muelas" y luego dar el lugar y la descripción. Esto es lo que están tratando de decir y es mucho más claro sin tantas especificaciones. "Sólo yo puedo tener un verdadero dolor de muelas" o bien tiene un significado de sentido común, o si es una proposición gramatical (filosófica), entonces es el enunciado de una regla; pretende decir "yo quisiera poner 'hay un verdadero dolor de muelas', o 'yo tengo dolor de muelas' en lugar de "yo tengo un verdadero dolor de muelas" ". Por consiguiente la regla no permite que se diga "sólo yo tengo un verdadero dolor de muelas". Pero el filósofo tiende a decir aquello que su propia regla le ha justamente prohibido decir, usando las mismas palabras que aquellas con las cuales acaba de enunciar la regla.

"Yo no puedo saber si otra persona tiene un dolor de muelas" parece indicar una barrera entre mi persona y la otra. Yo quiero hacerte ver que éste es un seudoproblema. Es nuestro lenguaje el que hace creer que existe una barrera. 
Aun una lectura rápida de estas palabras muestra una serie de tendencias diferentes en el pensamiento de Wittgenstein acerca de la filosofía. Así, Wittgenstein describe la cuestión de si es posible saber que otra persona tiene un dolor como un "seudocuestión". También está la sugerencia de que un problema filosófico es un cierto tipo de confusión, el síntoma lingüístico de un calambre mental. Está además la idea de que las teorías filosóficas, o cuando menos algunas teorías filosóficas, introducen formas alternativas de expresión que pueden traducirse a expresiones con uso ordinario, esto es, "que conservan el lenguaje ordinario y a su lado... colocan otro", siendo la diferencia entre ambas la de que "arreglan los hechos̀ en formas diferentes". Podría señalarse, para conectar lo que aquí dice Wittgenstein con otras cosas que afirma acerca de la filosofía, que es difícil ver cómo una notación alternativa podría en alguna forma ser un ataque al sentido común, que se curaría llevando otra vez los filósofos al lenguaje ordinario. $Y$ es igualmente difícil ver cómo una notación que usa 'las palabras 'flujo' y 'vaguedad' erróneamente, en una forma típicamente metafísica, a saber, sin una antítesis", puede traducirse al lenguaje ordinario en donde "en su uso correcto y cotidiano vaguedad se opone a claridad, flujo a estabilidad...". No es difícil ver, en verdad, que una notación que puede traducirse al lenguaje del sentido común no puede ser un ataque al sentido común; y no es difícil ver que una notación en la cual las palabras ordinarias aparecen sin sus antítesis no puede traducirse a un lenguaje, no puede tener "la misma multiplicidad" que un lenguaje en el que aparecen con sus antítesis. Todo esto sólo sirve para mostrar que en diferentes ocasiones y en conexiones algo diferentes, Wittgenstein puso a prueba diferentes ideas para explicar el enigma que es la filosofía.

Si no nos dejamos distraer por las diferentes ideas que se encuentran en el pasaje antes citado relativas a lo que hace el filósofo y cómo se mete en dificultades, llegamos a la noción no de que el filósofo no logra "abarcar en su conjunto el uso de nuestras palabras" sino de que las percepciones que tiene de los usos de las palabras hace que desee modificar o en alguna forma alterar esos usos. Es evidente que las alteraciones que él instituye no cumplen ninguna de las funciones que usualmente tienen las formas alternativas de expresión, por ejemplo, decir la misma cosa con mayor economía o con mayor eficacia para calcular o con mayor vivacidad o simplemente para evitar la monotonía de expresión. La imagen del filósofo que comienza a perfilarse es la de alguien que escudriña el intrincado mapa del lenguaje y que a diferencia del gramático y del compilador de thesaurus, no se satisface simplemente con informar de las reglas implícitas en el lenguaje, sino que, de variadas maneras, cambia las reglas. Diferencias en los usos de expresiones que el lenguaje ordinario no despliega en forma clara, diferencias que el lenguaje ordinario "se calla", el filósofo a veces está impulsado a destacarlas de manera nítida; y a veces está inclinado a silenciar ciertas diferencias en los usos de expresiones que el lenguaje ordinario "subraya". Las razones, formuladas en forma de argumento, que da para justificar los cambios que introduce, 
obviamente establecen pocas o ningunas conexiones con los tipos de funciones cotidianas que el lenguaje lleva a cabo para nosotros. La conclusión, que cuando menos se encuentra latente en muchas cosas que él dijo, es la de que un filósofo altera el lenguaje ordinario o "coloca otro lenguaje a su lado" en razón de los notables efectos que se crean al hacer esto. En el pasaje antes citado se representa al lenguaje ordinario como responsable de la idea de que existe una barrera entre la gente que impide que una persona sepa que otra tiene un dolor. Pero debe advertirse de inmediato que las oraciones "yo no puedo saber si otra persona tiene un dolor de muela", esto es, la oración que crea la idea de una barrera, no es una oración ordinaria. Wittgenstein, desde luego, estaba consciente de que el lenguaje ordinario no pone esta idea en la cabeza del "hombre de la calle": con palabra suyas "no sentimos estas dificultades en la vida ordinaria". Dicha oración es un producto filosófico cuya función no es en manera alguna semejante a la de una oración como "Yo no puedo saber si Sócrates tiene un dolor de muelas"; él soporta el dolor con estoicismo. Para describir lo que sucede a la manera de Wittgenstein, un filósofo que dice "Yo no puedo saber si otra persona tiene un dolor" está objetando el uso convencional de "tiene un dolor", pero no está consciente de que está objetando una convención. Su oración anuncia la exclusión del lenguaje de frases como "sabe que otra persona tiene un dolor", "sabe que otra persona está enojada", y en esta forma resalta las grandes diferencias entre el uso de "tiene un dolor" y el uso de "tiene una muela". Pero él introduce esta reestructuración de las convenciones lingüísticas en una forma tal que crea la idea de que hay algún tipo de barrera entre las gentes. No es el lenguaje cotidiano, sino lo forma como anuncia los cambios en el lenguaje cotidiano la que es responsable de la idea errónea.

Guando Wittgenstein dijo "Lo que nosotros destruimos sólo son castillos de arena y limpiamos el suelo del lenguaje sobre el que se asientan", es muy posible que lo que quería comunicar era que una teoría filosófica, al igual que el uso simulado de la arena como material de construcción, está constituido por un uso simulado del lenguaje. Es muy probable que quería comunicar la idea de que expresar una teoría filosófica no es usar el lenguaje para expresar una teoría, sino es únicamente usar el lenguaje para crear la idea falsa de que se está expresando una teoría. Y cuando observó que "podemos estar irresistiblemente atraídos por una notación", podría haber estado refiriéndose a cosas más profundas que se encuentran en nuestra mente y que las expresiones filosóficas enlazan. No es fácil saber dónde uno está interpretando demasiado y dónde está interpretando demasiado poco la mente de un pensador original.

MORRIS LAZEROWITZ.

\section{Smith College}

(traducción de Alejandro Rossi) 